January 2015

\title{
Gender differences in clinical characteristics and outcome of acute heart failure in sub-Saharan Africa: results of the THESUS-HF study
}

Okechukwu S. Ogah

University of the Witwatersrand

Beth A. Davison

Momentum Research, Inc

Karen Sliwa

University of the Witwatersrand

Bongani M. Mayosi

University of Cape Town

Albertino Damasceno

Eduardo Mondlane University

See next page for additional authors

Follow this and additional works at: http://ecommons.aku.edu/eastafrica_fhs_mc_intern_med Part of the Internal Medicine Commons

\section{Recommended Citation}

Ogah, O. S., Davison, B. A., Sliwa, K., Mayosi, B. M., Damasceno, A., Sani, M. U., Mondo, C., Dzudie, A., Ojji, D. B., Kouam, C., Suliman, A., Schrueder, N., Yonga, G., Abdou Ba, S., Maru, F., Alemayehu, B., Edwards, C., Cotter, G. (2015). Gender differences in clinical characteristics and outcome of acute heart failure in sub-Saharan Africa: results of the THESUS-HF study. Clinical Research in Cardiology, 104(6), 481-490.

Available at: http://ecommons.aku.edu/eastafrica_fhs_mc_intern_med/30 


\section{Authors}

Okechukwu S. Ogah, Beth A. Davison, Karen Sliwa, Bongani M. Mayosi, Albertino Damasceno, Mahmoud U. Sani, Charles Mondo, Anastase Dzudie, Dike B. Ojji, Charles Kouam, Ahmed Suliman, Neshaad Schrueder, Gerald Yonga, Sergine Abdou Ba, Fikru Maru, Bekele Alemayehu, Christopher Edwards, and Gad Cotter 


\title{
Gender differences in clinical characteristics and outcome of acute heart failure in sub-Saharan Africa: results of the THESUS-HF study
}

\author{
Okechukwu S. Ogah • Beth A. Davison - Karen Sliwa - Bongani M. Mayosi • Albertino Damasceno • \\ Mahmoud U. Sani · Charles Mondo · Anastase Dzudie · Dike B. Ojji • Charles Kouam • Ahmed Suliman • \\ Neshaad Schrueder • Gerald Yonga - Sergine Abdou Ba • Fikru Maru • Bekele Alemayehu • \\ Christopher Edwards $\cdot$ Gad Cotter
}

Received: 27 July 2014/ Accepted: 8 January 2015/Published online: 22 January 2015

(c) Springer-Verlag Berlin Heidelberg 2015

\begin{abstract}
Background The impact of gender on the clinical characteristics, risk factors, co-morbidities, etiology, treatment and outcome of acute heart failure in sub-Saharan Africa has not been described before. The aim of this study was to evaluate the sex differences in acute heart failure in subSaharan Africa using the data from The sub-Saharan Africa Survey of Heart Failure (THESUS-HF).

Methods and results 1,006 subjects were recruited into this prospective multicenter, international observational heart failure survey. The mean age of total population was
\end{abstract}

Electronic supplementary material The online version of this article (doi:10.1007/s00392-015-0810-y) contains supplementary material, which is available to authorized users.

O. S. Ogah ( $\square)$

Division of Cardiovascular Medicine, Department of Medicine, University College Hospital, Ibadan 5116, Nigeria

e-mail: osogah56156@gmail.com

O. S. Ogah · K. Sliwa

Soweto Cardiovascular Research Unit, University of the Witwatersrand, Johannesburg, South Africa

B. A. Davison - C. Edwards · G. Cotter

Momentum Research, Inc, 3100 Tower Boulevard, Suite 801, Durham, NC 27707, USA

K. Sliwa

Department of Medicine, Faculty of Health Sciences, Hatter Institute for Cardiovascular Research in Africa and the Institute of Infectious Disease and Molecular Medicine, University of

Cape Town, Cape Town, South Africa

B. M. Mayosi · N. Schrueder

Department of Medicine, Faculty of Medicine, GF Jooste and Groote Schuur Hospitals, University of Cape Town, Cape Town, South Africa
52.4 years (54.0 years for men and 50.7 years for women). The men were significantly older $(p=0.0045)$. Men also presented in poorer NYHA functional class (III and IV), $p=0.0364$ ). Cigarette smoking and high blood pressure were significantly commoner in men ( 17.3 vs. $2.6 \%$ and 60.0 vs. $51.0 \%$ respectively). On the other hand, atrial fibrillation and valvular heart disease were significantly more frequent in women. The mean hemoglobin concentration was lower in women compared to men (11.7 vs. $12.6 \mathrm{~g} / \mathrm{dl}, p \leq 0.0001)$, while the blood urea and creatinine levels were higher in men $(p<0.0001)$. LV systolic dysfunctional was also seen more in men. Men also had higher E/A ratio indicating higher LV filling pressure. Outcomes were similar in both sexes.

\section{A. Damasceno \\ Division of Cardiology, Department of Medicine, Eduardo \\ Mondlane University, Maputo, Mozambique}

\section{U. Sani}

Department of Medicine, Bayero University Kano/Aminu Kano

Teaching Hospital, Kano, Nigeria

C. Mondo

Uganda Heart Institute, Kampala, Uganda

A. Dzudie · C. Kouam

Department of Internal Medicine, Buea Faculty of Health

Sciences, Cardiology Unit, Douala General Hospital, Douala,

Cameroon

D. B. Ojji

Department of Medicine, University of Abuja Teaching

Hospital, Abuja, Nigeria 
Conclusions Although the outcome of patients admitted for AHF in sub-Saharan regions is similar in men and women, some gender differences are apparent suggesting that in men more emphasis should be put on modifiable life risk factors, while in women prevention of rheumatic heart diseases and improved nutrition should be addressed vigorously.

Keywords Gender $\cdot$ Sex $\cdot$ Heart failure $\cdot$ Africa

\section{Introduction}

Heart failure (HF) is a global public health problem [1]. In the United States alone, more than 5.8 million persons are affected $[2,3]$ while over 23-million individuals have been estimated to have HF worldwide [2]. Furthermore, about 2.4 million hospital admissions in the US are related to HF as primary and secondary diagnoses every year [3]. The cost of HF consumes up to 39 million dollars in the US each year [3]. The data from Europe or Japan are similar [4]. Prognosis is poor. Mortality risk after HF admission is $11.3 \%$ at 1 month, $33.1 \%$ at 1 year, and over $50 \%$ at 5 years [3].

Major HF registries have shown that women compared to men are older, have higher frequency of hypertension as etiological cause, are less likely to have coronary artery disease (CAD) and have higher mean ejection fraction (EF), and are also more likely to have heart failure with normal EF than men [5-9].

Differences between the sexes with respect to the etiology, risk factors, co-morbidities, management and outcome in patients with HF have not been described in subSaharan African populations.

\section{Study aims}

The aim of this report is, therefore, to explore the sex differences in the clinical characteristics, treatment and prognosis of HF using the data from The sub-Saharan Africa Survey of Heart Failure (THESUS-HF) [10].

\footnotetext{
A. Suliman

Faculty of Medicine, University of Khartoum, Khartoum, Sudan

G. Yonga

Department of Medicine, Aga Khan University, Nairobi, Kenya
}

\section{S. A. Ba $\cdot$ F. Maru}

Service de Cardiologie, Faculte de medecine de Dakar,

Ibadan 5116, Nigeria

B. Alemayehu

Addis Cardiac Hospital, Addis Ababa, Ethiopia

\section{Materials and methods}

Design and setting

The THESUS-HF registry [10] was a prospective multicenter, international observational survey of $\mathrm{HF}$ in 12 Cardiology Units from nine sub-Saharan African countries which included Cameroon, Ethiopia, Kenya, Mozambique, Nigeria, Senegal, South Africa, Sudan and Uganda. Ethics approval was obtained from the institutional ethics committee, subjects gave informed written consent and the study conformed to international standards as enshrined by the Helsinki declaration [11].

\section{Data collection}

Data were collected with the use of uniform and standardized case report forms. The primary cause of HF was based on the European Society of Cardiology (ESC) guidelines $[12,13]$. An exhaustive materials and methods of the survey have been published elsewhere [10].

In brief, information obtained included socio-demographic data, cardiovascular risk factors, medical history/ co-morbid conditions, etiological risk factors, in-hospital treatment, length of hospital stay (LOS), in-hospital outcome as well as outcome at 1,3 and 6 months. Also collected were laboratory investigations such as blood tests, 12-lead ECG and echocardiography.

All the echocardiograms were performed according to the guidelines of the American Society of Echocardiography $[14,15]$. An ejection fraction (LV ejection fraction estimated by Simpson's method) of $\geq 50 \%$ was used to identify HF with normal ejection fraction.

Subjects were eligible to participate if they were 12 years or older and admitted with clinical symptoms and signs suggestive of HF. All the cases (de novo or decompensated chronic HF) were confirmed by echocardiography. The exclusion criteria included patient with acute STsegment myocardial infarction, dialysis-dependent chronic renal disease, nephrotic syndrome, hepatic failure and other causes of hypoalbuminemia. Diagnoses of etiologic conditions were based on standard criteria as previously reported [10]. Specifically peripartum cardiomyopathy (PPCM) was diagnosed based on published guidelines $[16,17]$.

Statistical analysis

Data were managed centrally at Momentum Research Inc., Durham, USA. Categorical variables are presented as proportions, while continuous variables are presented as mean (SD) or median (inter quartile range -25 th and 75 th percentiles). 
Comparison of continuous variables was with 2-tailed, 2-sampled $t$ test while Chi square statistics were used for the comparison of categorical variables between men and women. Mortality and readmission rates were estimated using the Kaplan-Meier method.

The data for the whole cohort were compared according to gender. This was further analyzed after excluding women who had PPCM.

A 2-tailed $p$ value of $<0.05$ was assumed as statistically significant. SAS software (SAS, version 9.2; SAS Institute, Inc. USA) was used for analysis.

\section{Results}

One thousand and six subjects were recruited into the study (494 men and 511 women, the sex of one subject was not reported). The mean age of study population was 52.4 years (54.0 years for men and 50.7 years for women).The men were significantly older $(p=0.0045)$, but not so when 74 women with PPCM were excluded $(p=0.647)($ Table 1).

The age distribution according to gender is shown in Figs. 1 and 2. Over $98 \%$ of the cohort was Blacks. The mean body mass index was $24.9 \mathrm{~kg} / \mathrm{m}^{2}$ and this was similar in both sexes even after excluding those with PPCM. History of previous admission for HF was commoner in men (24.7 vs. $19.6 \%, p=0.0502,0.286$ after excluding women with PPCM). Men also had a poorer NYHA functional class (III and IV) 1 month before admission, $p=0.0364,0.0220$ after excluding women with PPCM).

In terms of cardiovascular risk factors and past medical history, cigarette smoking and high blood pressure were significantly reported more in men (17.3 vs. 2.6 and 60.0 vs. $51.0 \%$ respectively). The gender difference in high blood pressure prevalence became insignificant after removing women with PPCM.

On the other hand, atrial fibrillation and valvular heart disease were significantly more frequent in women, especially when women with PPCM were excluded (Table 1).

The mean heart and respiratory rates were significantly higher in women (105.7 vs. 101.6 beats/min, 31.3 vs. 30.0 cycles/min, respectively).

Table 2 shows the baseline laboratory profile of the subjects on admission in terms of gender.

The mean hemoglobin concentration was lower in women compared to men ( 11.7 vs. $12.6 \mathrm{~g} / \mathrm{dl}, p \leq 0.0001$ ) while the blood urea and creatinine levels were higher in men $(p<0.0001)$.

Table 3 and supplemental Table 1 depict the sex distribution of echocardiographic variables. Virtually, all the echocardiographic parameters were significantly higher in men compared to women.
In terms of valvular dysfunction, aortic lesions were more frequent in men. Left ventricular (LV) systolic dysfunctional was also seen more in men. Men also had higher E/A ratio indicating higher LV filling pressure. $L V$ ejection fraction was also significantly lower in men.

Etiology-wise, (Table 4), women had higher rates of rheumatic heart disease, endomyocardial fibrosis and human immunodeficiency virus (HIV)-associated cardiomyopathy while hypertensive HF, dilated cardiomyopathy and ischemic heart disease were common in men.

The major 12-lead ECG findings according to gender are shown in supplemental Table 2. As previously stated atrial fibrillation was significantly commoner in women ( $27.5 \mathrm{vs.}$ $19.5 \%, p=0.0338)$, especially after excluding those women with PPCM $(p=0.0049)$ while ST-T changes were observed more in men (36.9 vs. $25.8 \%, p=0.0066$ and 0.0002 after excluding those with PPCM).

\section{Medications}

Supplemental Tables 3 and 4 show the medications on admission and discharge, respectively, according to gender. Women more frequently received digitalis compounds than men (15.8 vs. $11.4 \%, p=0.0416)$.

\section{Outcome}

Table 5 shows the outcome variables. These are similar in men and women even after excluding women with PPCM. Figure 3 shows the survival curves according to gender.

\section{Discussion}

Our study revealed some sex differences in African subjects with AHF. Men were older than the women. HF was generally commoner in women especially before the age of 50 years. From the age of 50-70 years, it tended to be more frequent in men. Previous history of HF (acute on chronic HF) was seen more in men. The burden of CV risk factors such as hypertension and cigarette smoking was higher in men. Anemia was reported more frequently in women while renal impairment was more frequent in men. Echocardiographic parameters were more abnormal in men and there were some differences in the etiology of HF in men and women. Atrial fibrillation was commoner in women while left ventricular hypertrophy (LVH), ECG features of ischemic and ST-T abnormalities were commoner in men. Although health outcomes were slightly worse in men, these were not statistically significant.

In the Euro-HF survey, HF was less frequently diagnosed in women (39\%) [18]. Women were generally older than men in all the HF registries in high-income countries 
Table 1 Baseline socio-demographic characteristics profile of the patients by gender

\begin{tabular}{|c|c|c|c|c|c|c|}
\hline Characteristic & Total $(n=1,006)$ & Male $(n=494)$ & $\begin{array}{l}\text { Female } \\
(n=511)\end{array}$ & $P$ value* & $\begin{array}{l}\text { Female (excluding } \\
\text { peripartum CM) } \\
(n=437)\end{array}$ & $P$ value** \\
\hline $\begin{array}{l}\text { Age (years), mean (SD), } \\
\text { 25th percentile, median, } \\
\text { 75th percentile }\end{array}$ & $\begin{array}{l}52.4(18.3) 39.0 \\
55.0,67.0\end{array}$ & $\begin{array}{l}54.0(16.9) 43.0 \\
55.0,67.0\end{array}$ & $\begin{array}{l}50.7(19.5) 33.0 \\
53.0,67.0\end{array}$ & 0.0045 & $\begin{array}{l}54.6(18.3) 41.0 \\
58.0,70.0\end{array}$ & 0.6473 \\
\hline$>65$ years $(n / \%)$ & $269(26.7 \%)$ & $134(27.1 \%)$ & $135(26.4 \%)$ & 0.8003 & $135(30.9 \%)$ & 0.2057 \\
\hline \multicolumn{7}{|l|}{ Race } \\
\hline Black $(n / \%)$ & $984(98.5 \%)$ & $486(98.8 \%)$ & $497(98.2 \%)$ & 0.4680 & $423(97.9 \%)$ & 0.2999 \\
\hline BMI $\left(\mathrm{kg} / \mathrm{m}^{2}\right)$, mean $(\mathrm{SD})$ & $24.9(5.8)$ & $24.7(5.0)$ & $25.1(6.5)$ & 0.2583 & $25.4(6.7)$ & 0.0604 \\
\hline $\begin{array}{l}\text { Admitted for HF in } \\
12 \text { months prior to } \\
\text { admission }\end{array}$ & $222(22.1 \%)$ & $122(24.7 \%)$ & $100(19.6 \%)$ & 0.0502 & $95(21.7 \%)$ & 0.2868 \\
\hline $\begin{array}{l}\text { No. of } \mathrm{HF} \text { admissions in } \\
\text { prior } 12 \text { months, mean } \\
\text { (SD) }\end{array}$ & $0.37(0.78)$ & $0.41(0.77)$ & $0.34(0.78)$ & 0.1523 & $0.38(0.82)$ & 0.5280 \\
\hline \multicolumn{7}{|c|}{ NYHA class 1 month before admission $(n / \%)$} \\
\hline $\mathrm{I}$ & $121(18.1 \%)$ & $59(18.0 \%)$ & $62(18.2 \%)$ & 0.0364 & $49(16.1 \%)$ & 0.0220 \\
\hline II & $303(45.3 \%)$ & $133(40.6 \%)$ & $170(50.0 \%)$ & & $157(51.6 \%)$ & \\
\hline III & $217(32.4 \%)$ & $118(36.0 \%)$ & $98(28.8 \%)$ & & $90(29.6 \%)$ & \\
\hline IV & $28(4.2 \%)$ & $18(5.5 \%)$ & $10(2.9 \%)$ & & $8(2.6 \%)$ & \\
\hline \multicolumn{7}{|c|}{$\mathrm{CV}$ risk factors, past medical history } \\
\hline Smoking $(n / \%)$ & $98(9.8 \%)$ & $85(17.3 \%)$ & $13(2.6 \%)$ & $<0.0001$ & $12(2.8 \%)$ & $<0.0001$ \\
\hline Hypertension $(n / \%)$ & $556(55.5 \%)$ & $296(60.0 \%)$ & $259(51.0 \%)$ & 0.0040 & $255(58.6 \%)$ & 0.6603 \\
\hline $\begin{array}{l}\text { Peripheral vascular } \\
\text { disease }(n / \%)\end{array}$ & $12(1.2 \%)$ & $9(1.8 \%)$ & $3(0.6 \%)$ & 0.0732 & $3(0.7 \%)$ & 0.1282 \\
\hline Stroke $(n / \%)$ & $25(2.5 \%)$ & $10(2.0 \%)$ & $15(2.9 \%)$ & 0.3513 & $11(2.5 \%)$ & 0.6095 \\
\hline Hyperlipidemia $(n / \%)$ & $90(9.2 \%)$ & $52(10.8 \%)$ & $38(7.6 \%)$ & 0.0852 & $35(8.2 \%)$ & 0.1888 \\
\hline Atrial fibrillation $(n / \%)$ & $184(18.4 \%)$ & $77(15.7 \%)$ & $107(21.1 \%)$ & 0.0283 & $107(24.7 \%)$ & 0.0006 \\
\hline $\begin{array}{l}\text { Ischemic heart disease } \\
(n / \%)\end{array}$ & $82(8.2 \%)$ & $46(9.3 \%)$ & $36(7.1 \%)$ & 0.1893 & $36(8.3 \%)$ & 0.5648 \\
\hline $\begin{array}{l}\text { Valvular heart disease } \\
(n / \%)\end{array}$ & $272(27.2 \%)$ & $113(22.9 \%)$ & $159(31.4 \%)$ & 0.0025 & $153(35.4 \%)$ & $<0.0001$ \\
\hline Cardiomyopathy (n/\%) & $416(41.9 \%)$ & $200(40.9 \%)$ & $216(42.9 \%)$ & 0.5320 & $158(36.7 \%)$ & 0.1974 \\
\hline Cor pulmonale $(n / \%)$ & $72(7.2 \%)$ & $36(7.4 \%)$ & $36(7.1 \%)$ & 0.8872 & $35(8.1 \%)$ & 0.6744 \\
\hline Pacemaker $(n / \%)$ & $4(0.4 \%)$ & $4(0.8 \%)$ & $0(0.0 \%)$ & 0.0580 & $0(0 \%)$ & 0.1270 \\
\hline Pericardial disease $(n / \%)$ & $53(5.3 \%)$ & $29(5.9 \%)$ & $24(4.7 \%)$ & 0.4132 & $20(4.6 \%)$ & 0.3875 \\
\hline Diabetes mellitus $(n / \%)$ & $114(11.4 \%)$ & $58(11.8 \%)$ & $56(11.0 \%)$ & 0.6790 & $52(11.9 \%)$ & 0.9584 \\
\hline Depression $(n / \%)$ & $33(3.3 \%)$ & $15(3.0 \%)$ & $18(3.5 \%)$ & 0.6572 & $18(4.1 \%)$ & 0.3654 \\
\hline Dementia $(n / \%)$ & $22(2.2 \%)$ & $9(1.8 \%)$ & $13(2.6 \%)$ & 0.4342 & $13(3.0 \%)$ & 0.2475 \\
\hline Malignancy $(n / \%)$ & $13(1.3 \%)$ & $5(1.0 \%)$ & $8(1.6 \%)$ & 0.4399 & $8(1.8 \%)$ & 0.2896 \\
\hline \multicolumn{7}{|l|}{ Symptoms on admission } \\
\hline Orthopnea, mean $(\mathrm{SD})^{\mathrm{a}}$ & $2.31(0.76)$ & $2.33(0.76)$ & $2.29(0.75)$ & 0.5298 & $2.24(0.77)$ & 0.0961 \\
\hline \multicolumn{7}{|l|}{ Signs on admission } \\
\hline $\begin{array}{l}\text { Peripheral edema, mean } \\
(\mathrm{SD})^{\mathrm{b}}\end{array}$ & $1.83(1.04)$ & $1.87(1.05)$ & $1.78(1.03)$ & 0.1844 & $1.73(1.05)$ & 0.0394 \\
\hline Rales, mean $(\mathrm{SD})^{\mathrm{c}}$ & $1.68(0.92)$ & $1.66(0.90)$ & $1.70(0.94)$ & 0.4981 & $1.68(0.97)$ & 0.7197 \\
\hline $\begin{array}{l}\text { Temperature }\left({ }^{\circ} \mathrm{C}\right), \\
\text { mean }(\mathrm{SD})\end{array}$ & $36.7(0.6)$ & $36.7(0.7)$ & $36.6(0.6)$ & 0.1980 & $36.6(0.6)$ & 0.1629 \\
\hline $\begin{array}{l}\text { Respiratory rate (changed } \\
\text { to b/min), mean (SD) }\end{array}$ & $30.7(7.9)$ & $30.0(7.5)$ & $31.3(8.3)$ & 0.0120 & $31.1(8.6)$ & 0.0484 \\
\hline
\end{tabular}


Table 1 continued

\begin{tabular}{|c|c|c|c|c|c|c|}
\hline Characteristic & Total $(n=1,006)$ & Male $(n=494)$ & $\begin{array}{l}\text { Female } \\
(n=511)\end{array}$ & $P$ value* & $\begin{array}{l}\text { Female (excluding } \\
\text { peripartum CM) } \\
(n=437)\end{array}$ & $P$ value** \\
\hline Heart rate, mean (SD) & $103.7(21.6)$ & $101.6(21.4)$ & $105.7(21.6)$ & 0.0029 & $103.8(21.9)$ & 0.1316 \\
\hline $\begin{array}{l}\text { Systolic blood pressure } \\
(\mathrm{mmHg}), \text { mean }(\mathrm{SD})\end{array}$ & $130.4(33.5)$ & $132.4(33.7)$ & $128.5(33.4)$ & 0.0611 & $131.4(34.0)$ & 0.6425 \\
\hline $\begin{array}{l}\text { Diastolic blood pressure } \\
\quad(\mathrm{mmHg}) \text {, mean }(\mathrm{SD})\end{array}$ & $84.3(20.9)$ & $85.5(21.2)$ & $83.2(20.7)$ & 0.0840 & $84.1(21.3)$ & 0.3093 \\
\hline $\begin{array}{l}\text { Pulse pressure }(\mathrm{mmHg}) \\
\text { mean }(\mathrm{SD})\end{array}$ & $46.2(19.7)$ & $47.0(19.4)$ & $45.4(20.0)$ & 0.1982 & $47.3(20.4)$ & 0.8037 \\
\hline $\begin{array}{l}\text { Oxygen saturation, mean } \\
\text { (SD) }\end{array}$ & $93.3(6.4)$ & $93.3(5.5)$ & $93.2(7.0)$ & 0.8442 & $93.1(7.4)$ & 0.6671 \\
\hline
\end{tabular}

Values reported as mean (SD) for continuous variables and $n(\%)$ for categorical. Median, 25th, and 75th percentiles given for skewed data

a Orthopnea scored as 0-none, 1-1 pillow $(10 \mathrm{~cm}), 2-2$ pillows $(20 \mathrm{~cm}), 3-3$ pillows $(>30 \mathrm{~cm})$

b Peripheral edema scored as 0-complete absence of skin indentation with mild digital pressure in all dependent areas, 1-indention of skin that resolves over 10-15 s, 2-indention of skin is easily created with limited pressure and disappears slowly (15-30 s or more), 3-large areas of indentation easily produced and slow to resolve ( $>30 \mathrm{~s})$

${ }^{c}$ Rales scores as 0-no rales after clearing with cough, 1-moist or dry rales heard in lower 1/3 of 1 or both lung fields that persist after cough, 2-moist or dry rales heard throughout the lower half to $2 / 3$ of 1 or both lung fields, 3-moist or dry rales heard throughout both lung fields

* (Chi Square for categorical, $t$ test for continuous) male versus female

** (Chi Square for categorical, $t$ test for continuous) male versus female (excluding peripartum CM)

Fig. 1 Age distribution of the subjects by gender

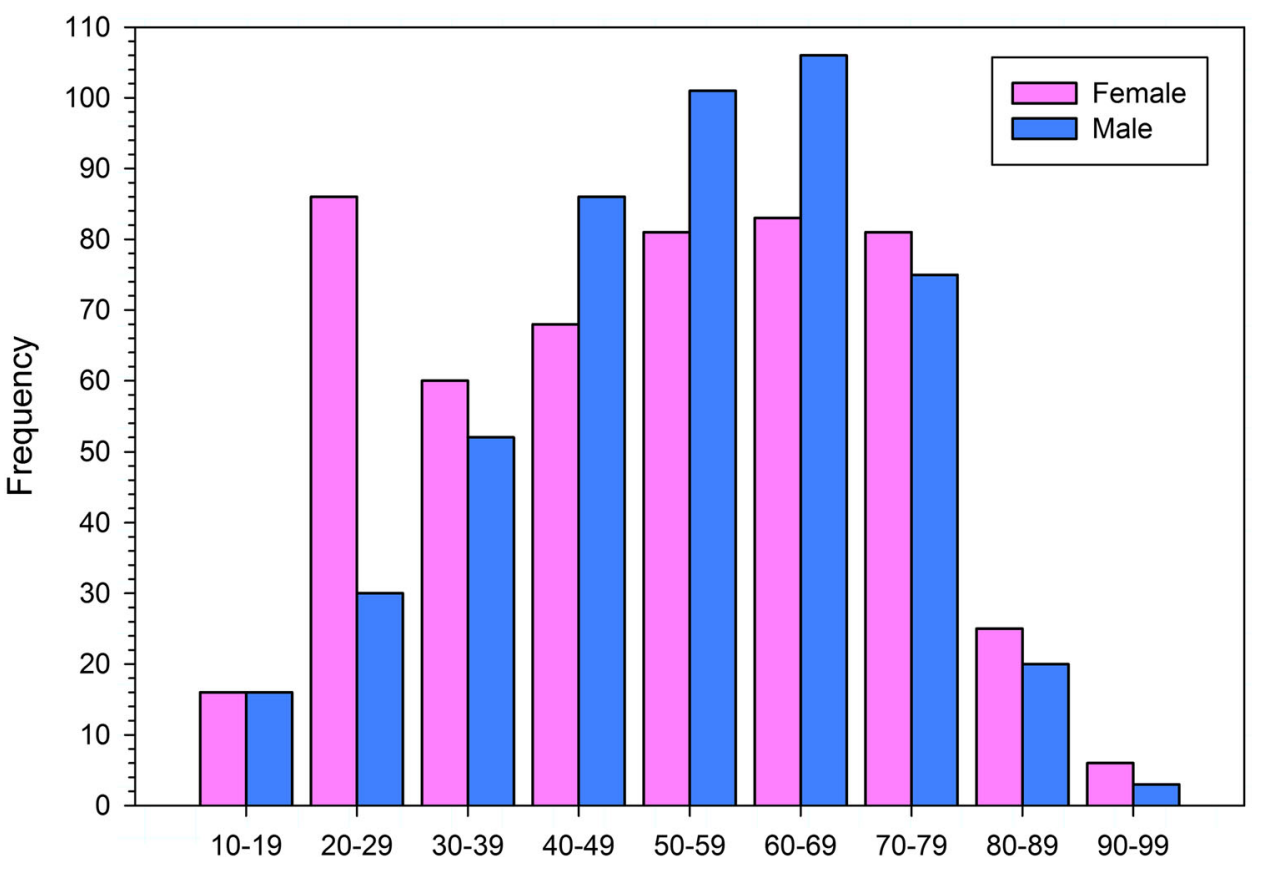

[5, 6, 8, 18]. For example, in the Japanese HF registry, female patients were a mean of 5.7 years older than the men [8]. In the acute heart failure database (AHEAD), the mean age of men and women was 68-70 and 73-75 years, respectively [19]. The finding of greater frequency of de novo $\mathrm{HF}$ in women in this study is consistent with the observation in the Euro-HF survey; however, our finding may have been driven by the frequency of PPCM [18]. The differences may also be related to the population structure in Africa compared to that of high-income countries of the world. The African population is very young compared to high-income countries where the age of onset of heart disease is generally after the age of 65 years [20, 21].

Cardiovascular risk factors such as, hypertension, cigarette smoking, coronary artery disease and chronic obstructive pulmonary disease (COPD) were seen more in 
Fig. 2 Age distribution of the subjects by gender (females excluding peripartum $\mathrm{CM}$ )

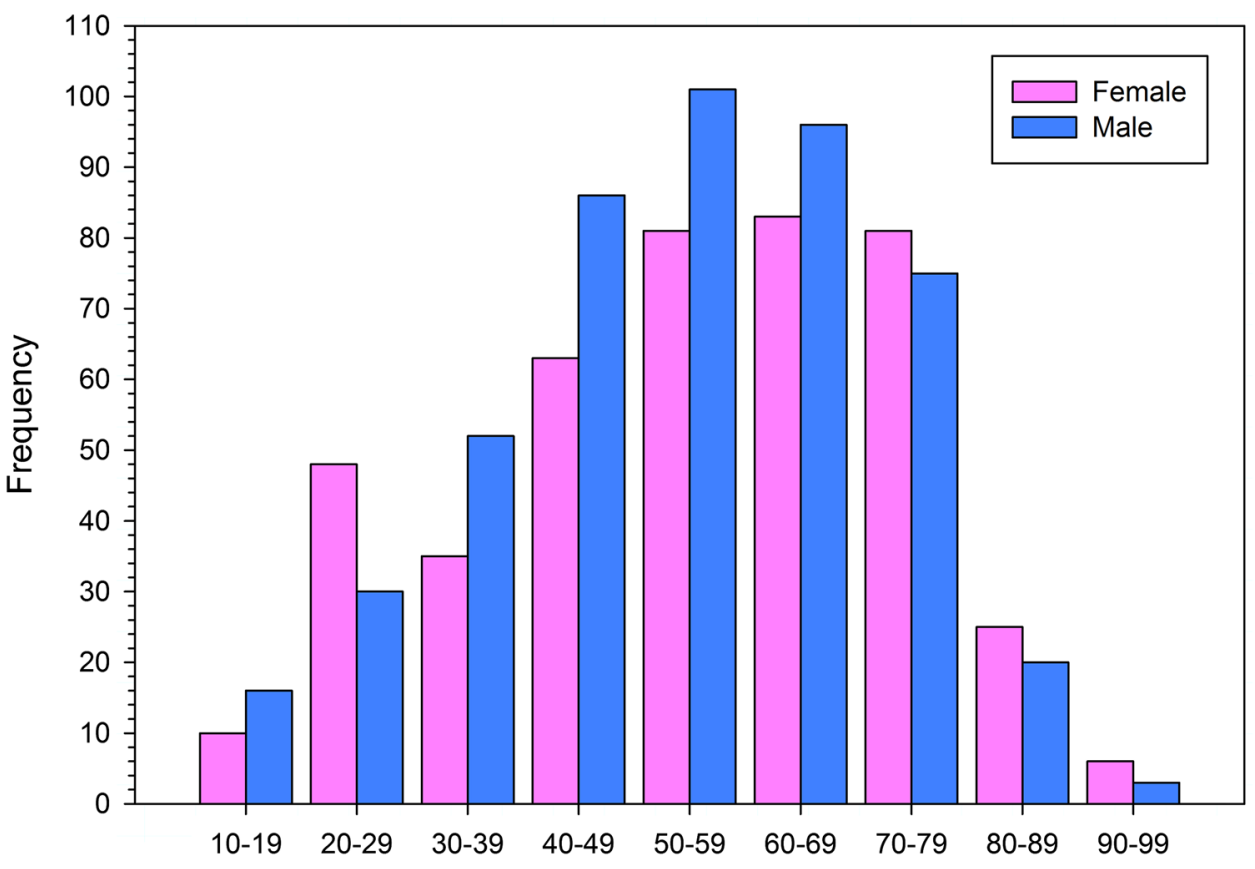

Table 2 Baseline laboratory profile of the subjects on admission according to gender

\begin{tabular}{|c|c|c|c|c|c|c|}
\hline Variable & $\begin{array}{l}\text { Total } \\
(n=1,006)\end{array}$ & $\begin{array}{l}\text { Male } \\
(n=494)\end{array}$ & $\begin{array}{l}\text { Female } \\
(n=511)\end{array}$ & $P$ value* & $\begin{array}{l}\text { Female (excluding } \\
\text { peripartum } \mathrm{CM}) \\
(n=437)\end{array}$ & $P$ value** \\
\hline \multicolumn{7}{|l|}{ Blood tests } \\
\hline Sodium $(\mathrm{mmol} / \mathrm{L})$, mean $(\mathrm{SD})$ & $946,135.1(6.6)$ & $463,134.9(6.5)$ & $482,135.3(6.8)$ & 0.3294 & $416,135.4(6.8)$ & 0.2818 \\
\hline Glucose (mg/dl), mean (SD) & $878,109.7(49.7)$ & $442,109.7(44.0)$ & $435,109.5(54.9)$ & 0.9420 & $380,112.5(57.6)$ & 0.4453 \\
\hline Hemoglobin $(\mathrm{g} / \mathrm{dl})$, mean $(\mathrm{SD})$ & $967,12.2(2.4)$ & $476,12.6(2.6)$ & $490,11.7(2.2)$ & $<0.0001$ & $418,11.8(2.2)$ & $<0.0001$ \\
\hline $\begin{array}{l}\text { Total white cell count } / \mathrm{mm}^{3} \text {, } \\
\text { mean }(\mathrm{SD})\end{array}$ & $\begin{array}{c}963,7,699.3 \\
(4,091.7)\end{array}$ & $\begin{array}{c}472,7,484.1 \\
(3,505.0)\end{array}$ & $\begin{array}{c}490,7,914.2 \\
(4,580.9)\end{array}$ & 0.1015 & $\begin{array}{c}418,7,972.0 \\
(4,743.4)\end{array}$ & 0.0847 \\
\hline Lymphocytes (\%), mean (SD) & $839,30.3(13.4)$ & $417,29.8(12.9)$ & $421,30.9(13.8)$ & 0.2497 & $366,30.3(13.7)$ & 0.6222 \\
\hline Blood urea (mg/dl), mean (SD) & $951,35.6(33.1)$ & $466,41.0(37.2)$ & $484,30.4(27.7)$ & $<0.0001$ & $417,31.9(29.2)$ & $<0.0001$ \\
\hline Creatinine (mg/dl), mean (SD) & $964,1.39(1.05)$ & $471,1.53(1.11)$ & $492,1.26(0.97)$ & $<0.0001$ & $421,1.3(1.0)$ & 0.0005 \\
\hline $\begin{array}{l}\text { Total cholesterol (mg/dl), } \\
\text { mean }(\mathrm{SD})\end{array}$ & $649,157.6(54.2)$ & $318,160.0(59.0)$ & $331,155.2(49.1)$ & 0.2648 & $279,157.8(50.3)$ & 0.6208 \\
\hline Triglyceride (mg/dl), mean (SD) & $640,106.2(53.9)$ & $316,109.8(56.7)$ & $324,102.7(50.9)$ & 0.0918 & $274,103.5(53.5)$ & 0.1678 \\
\hline $\begin{array}{l}\text { Peak creatine kinase (IU/L), } \\
\text { mean }(\mathrm{SD})\end{array}$ & $245,232.2(447.7)$ & $108,259.4(412.6)$ & $137,210.8(473.9)$ & 0.4004 & $121,222.5(501.0)$ & 0.5423 \\
\hline Peak CK- MB (IU/L), mean (SD) & $175,37.4(76.0)$ & $83,39.1(83.9)$ & $92,35.9(68.6)$ & 0.7831 & $88,36.0(70.1)$ & 0.7960 \\
\hline
\end{tabular}

* ( $t$ test) male versus female

** ( $t$ test) male versus female (excluding peripartum CM)

men. The higher rates of COPD in men may be related to higher rate of smoking. Occupations related to the development of COPD such as mining are also associated with men in Africa. Higher frequency of anemia in women may be related to menstruation as well as poorer nutrition.

In the Euro-HF survey, hypertension (67.4 vs. $59.4 \%$ ), diabetes (35 vs. $31.4 \%$ ) and anemia (18.5 vs. $12.4 \%$ ) were commoner in women [18]. As has been observed by other AHF registries [ $\left.\begin{array}{lll}5 & 8 & 18\end{array}\right]$, renal impairment is more frequent in men. This may be related to longer duration of $\mathrm{CV}$ risk factors such as hypertension, higher frequency of acute or chronic HF as well as higher burden of peripheral vascular disease in men compared to women.

Men also had higher frequency of severe symptoms (New York Heart Association (NYHA) classes III and IV), 
Table 3 Echocardiography by gender (excluding PPCM)

\begin{tabular}{|c|c|c|c|c|c|}
\hline Echocardiography & All $(n=954)$ & $\operatorname{Men}(n=469)$ & $\begin{array}{l}\text { Female } \\
\text { (excluding } \\
\text { peripartum } \mathrm{CM}) \\
(n=413)\end{array}$ & $\begin{array}{l}\text { OR }(95 \% \mathrm{CI}) \text { for } \\
\text { categorical, mean } \\
\text { difference }(95 \% \mathrm{CI}) \\
\text { for continuous }\end{array}$ & $\begin{array}{l}P \text { value (Chi square } \\
\text { for categorical, } t \text { test } \\
\text { for continuous) }\end{array}$ \\
\hline LA diameter (mm), mean (SD) & $47.1(9.1)$ & $47.8(8.6)$ & $47.2(9.7)$ & $-0.55(-1.80,0.71)$ & 0.3922 \\
\hline LA area $\left(\mathrm{mm}^{2}\right)$, mean $(\mathrm{SD})$ & 2,776.1 (934.7) & $2,880.2(872.3)$ & $2,703.8(1,012.4)$ & $-176.40(-343.90,-8.93)$ & 0.0390 \\
\hline IVSTd (mm), mean (SD) & $11.2(3.2)$ & $11.7(3.2)$ & $11.2(3.1)$ & $-0.49(-0.91,-0.06)$ & 0.0250 \\
\hline PWTd (mm), mean (SD) & $10.7(2.9)$ & $11.2(2.9)$ & $10.7(2.7)$ & $-0.50(-0.88,-0.16)$ & 0.0106 \\
\hline LVIDd (mm), mean (SD) & $57.7(11.6)$ & $59.6(11.4)$ & $55.0(11.7)$ & $-4.55(-6.08,-3.01)$ & $<0.0001$ \\
\hline LVIDs (mm), mean (SD) & $46.1(13.2)$ & $48.2(12.9)$ & $42.5(13.1)$ & $-5.73(-7.46,-4.00)$ & $<0.0001$ \\
\hline EA_ratio, mean (SD) & $2.02(2.33)$ & $2.26(3.00)$ & $1.73(1.16)$ & $-0.53(-0.89,-0.17)$ & 0.0039 \\
\hline $\begin{array}{l}\text { E-wave deceleration time (ms), } \\
\text { mean (SD) }\end{array}$ & $150.2(92.9)$ & $147.5(98.2)$ & $162.0(92.0)$ & $14.49(0.22,28.76)$ & 0.0466 \\
\hline $\begin{array}{l}\text { A-wave duration }(\mathrm{ms}) \\
\text { mean }(\mathrm{SD})\end{array}$ & $126.1(45.0)$ & $124.3(42.0)$ & $132.8(48.8)$ & $8.53(0.30,16.77)$ & 0.0423 \\
\hline Aortic stenosis $(n / \%)^{\mathrm{a}}$ & $24(2.6 \%)$ & $15(3.3 \%)$ & $9(2.2 \%)$ & $1.51(0.65,3.48)$ & 0.3339 \\
\hline Aortic regurgitation $(n / \%)^{\mathrm{a}}$ & $83(8.9 \%)$ & $50(10.9 \%)$ & $31(7.6 \%)$ & $1.49(0.93,2.38)$ & 0.0961 \\
\hline Mitral stenosis $(n / \%)^{\mathrm{a}}$ & $51(5.5 \%)$ & $19(4.2 \%)$ & $32(8.0 \%)$ & $0.51(0.28,0.91)$ & 0.0206 \\
\hline Mitral regurgitation $(n / \%)^{\mathrm{a}}$ & $366(38.7 \%)$ & $178(38.5 \%)$ & $170(41.4 \%)$ & $0.89(0.68,1.17)$ & 0.3932 \\
\hline Tricuspid regurgitation $(n / \%)^{\mathrm{a}}$ & $266(28.2 \%)$ & $136(29.4 \%)$ & $114(27.8 \%)$ & $1.08(0.81,1.45)$ & 0.5947 \\
\hline Pericardial effusion $(n / \%)$ & $31(3.3 \%)$ & $13(2.9 \%)$ & $16(4.0 \%)$ & $0.71(0.34,1.51)$ & 0.3748 \\
\hline Ejection fraction, mean (SD) & $39.4(16.2)$ & 37.5 (15.7) & $43.4(16.1)$ & $5.85(3.69,8.01)$ & $<0.0001$ \\
\hline $\mathrm{LVEF} \geq 45 \%(n / \%)$ & $317(33.2 \%)$ & $134(28.6 \%)$ & $180(43.6 \%)$ & $0.52(0.39,0.68)$ & $<0.0001$ \\
\hline LVEF $30-44 \%(n / \%)$ & $299(31.3 \%)$ & $155(33.1 \%)$ & $128(31.0 \%)$ & $1.10(0.83,1.46)$ & \\
\hline LVEF $<30 \%(n / \%)$ & $278(29.1 \%)$ & $152(32.4 \%)$ & $85(20.6 \%)$ & $1.85(1.36,2.52)$ & \\
\hline
\end{tabular}

Subset of patients with echocardiography within 4 weeks prior to 2 weeks after admission

Mean (SD) or $n(\%)$ provided for continuous and categorical variable, respectively. $t$ test used to compare genders for continuous variables and Chi square test provided for categorical comparisons

${ }^{a}$ Percentages reported as those with moderate/severe vs. mild/none

higher rates of left atrial dilatation, LVH and LV systolic and diastolic dysfunction.

On the other hand, HF with normal EF was reported more often in women. This is consistent with previous reports. In the Euro-HF survey II, HF with preserved EF was observed twice as often in women than in men [18]. In another report, HF with normal EF was noted in up to $73 \%$ of women [22]. In high-income countries, this was attributed to higher frequency of hypertension and older age in women. This is not the case in our study. The reason for our observation may be related to higher burden of $\mathrm{CV}$ risk factors as well as advanced heart disease in men compared to women.

In terms of etiological risk factor for HF, except for valvular heart disease, all the other factors were more frequent in men. Higher burden of valvular heart disease in women has been reported by other workers [5, 18, 22]. This suggests that in men more emphasis should be placed on modification of risk factors while in women prevention of rheumatic heart diseases and improved nutrition should be addressed vigorously.
ECG abnormalities such as atrial fibrillation, ventricular extrasystoles and bundle-branch block were commoner in women while LVH, Q-waves and ST-T changes were more frequent in men.

The higher rates of arrhythmias especially atrial fibrillation in women may be related to the higher frequency of valvular heart disease [23, 24]. Hypertension and ischemic heart disease which are diagnosed more frequently in men may explain the higher burden of LVH and ST-T abnormalities in them [25-28].

On admission but not discharge, digitalis compounds were prescribed more in women, probably because of the higher prevalence of atrial fibrillation within this group. On the other hand, aspirin was prescribed more to men, possibly because of the greater frequency of ischemic changes on ECG. This picture has been documented by other workers $[5,8,18]$.

Health outcomes such as length of stay (LOS), intrahospital mortality rates, 30-day, 90-day and 180-day mortality were slightly higher in men compared to women. This, however, did not reach statistical significance. This is similar to the observation in the Japanese HF registry and 
Table 4 Primary etiology by gender

\begin{tabular}{llllc}
\hline Etiology & Total $(n=1,006)$ & Male $(n=494)$ & Female $(n=511)$ & $\begin{array}{l}\text { Female (excluding } \\
\text { peripartum CM) }(n=437)\end{array}$ \\
\hline Hypertensive CMP $(n / \%)$ & $396(40.4 \%)$ & $219(45.3 \%)$ & $176(35.6 \%)$ & $176(41.8 \%)$ \\
Idiopathic dilated CMP $(n / \%)$ & $136(13.9 \%)$ & $89(18.4 \%)$ & $47(9.5 \%)$ & $47(11.2 \%)$ \\
Rheumatic heart disease $(n / \%)$ & $140(14.3 \%)$ & $54(11.2 \%)$ & $86(17.4 \%)$ & $86(20.4 \%)$ \\
Ischemic heart disease $(n / \%)$ & $77(7.9 \%)$ & $48(9.9 \%)$ & $29(5.9 \%)$ & $29(6.9 \%)$ \\
Peripartum cardiomyopathy $(n / \%)$ & $74(7.7 \%)$ & 0 & $74(15.0 \%)$ & - \\
Pericardial effusion/tamponade $(n / \%)$ & $47(4.8 \%)$ & $25(5.2 \%)$ & $22(4.4 \%)$ & $22(5.2 \%)$ \\
HIV cardiomyopathy $(n / \%)$ & $23(2.4 \%)$ & $12(2.5 \%)$ & $11(2.2 \%)$ & $11(2.6 \%)$ \\
Endomyocardial fibrosis $(n / \%)$ & $13(1.3 \%)$ & $3(0.6 \%)$ & $10(2.0 \%)$ & $10(2.4 \%)$ \\
Other $(n / \%)$ & $73(7.5 \%)$ & $33(6.8 \%)$ & $40(8.1 \%)$ & $40(9.5 \%)$ \\
\hline
\end{tabular}

Table 5 Outcome variables according to gender

\begin{tabular}{|c|c|c|c|c|c|c|}
\hline Outcome & $\begin{array}{l}\text { All } \\
(n=1,006)\end{array}$ & $\begin{array}{l}\text { Men } \\
(n=494)\end{array}$ & $\begin{array}{l}\text { Women } \\
(n=511)\end{array}$ & $P$ value & $\begin{array}{l}\text { Female (excluding } \\
\text { peripartum } \mathrm{CM}) \\
(n=437)\end{array}$ & $P$ value** \\
\hline Length of hospital stay ${ }^{a}$ & $9.22(9.29)$ & $9.39(10.37)$ & $9.07(8.14)$ & 0.6081 & $9.00(8.08)$ & 0.5468 \\
\hline Intrahospital mortality rate ${ }^{\mathrm{b}}$ & $42(4.2 \%)$ & $24(4.9 \%)$ & $18(3.5 \%)$ & 0.2930 & $15(3.4 \%)$ & 0.2817 \\
\hline All-cause mortality through 30 days ${ }^{\mathrm{c}}$ & $54(5.7 \%)$ & $30(6.4 \%)$ & $24(5.0 \%)$ & 0.3481 & $20(4.9 \%)$ & 0.3311 \\
\hline All-cause mortality through 90 days ${ }^{\mathrm{c}}$ & $115(13.1 \%)$ & $59(13.5 \%)$ & $56(12.6 \%)$ & 0.6483 & $44(11.7 \%)$ & 0.3914 \\
\hline All-cause mortality through 180 days $^{\mathrm{c}}$ & $151(17.8 \%)$ & $77(18.3 \%)$ & $74(17.4 \%)$ & 0.6393 & $60(16.6 \%)$ & 0.4399 \\
\hline All-cause readmission through 30 days ${ }^{\mathrm{c}}$ & $24(2.8 \%)$ & $12(2.8 \%)$ & $12(2.7 \%)$ & 0.9308 & $11(2.9 \%)$ & 0.9293 \\
\hline All-cause readmission through 90 days ${ }^{\mathrm{c}}$ & $111(14.1 \%)$ & $56(14.4 \%)$ & $55(13.8 \%)$ & 0.7473 & $50(14.7 \%)$ & 0.9866 \\
\hline All-cause readmission through 180 days $^{\mathrm{c}}$ & $157(20.8 \%)$ & $74(19.9 \%)$ & $83(21.8 \%)$ & 0.6405 & $77(23.6 \%)$ & 0.3221 \\
\hline $\begin{array}{l}\text { All-cause death or readmission through } \\
60 \text { days }{ }^{c}\end{array}$ & $138(15.6 \%)$ & $73(16.6 \%)$ & $65(14.5 \%)$ & 0.3732 & $54(14.2 \%)$ & 0.3208 \\
\hline
\end{tabular}

${ }^{a}$ Mean (SD). $P$ value provided from $t$ test

b $N(\%) . P$ value provided from $\chi^{2}$ test

c $N(\mathrm{KM} \%) . P$ value provided from log-rank test

* Male versus female

** Male versus female (excluding peripartum CM)

in the Euro-HF survey II [18] and the United States registries [5, 29]. However, adjusted mortality was better in women in the AHEAD registry [19] and some other studies $[30,31]$.

\section{Limitations}

The fact that our registry was conducted in tertiary hospitals may indicate that our findings may not reflect what happens in the secondary or primary healthcare services in these African countries. The data may not, therefore, be inclusive and could only represent what happens in these tertiary institutions.
Confirmation of final diagnoses as well as echocardiographic parameters was done locally which is also a limitation. Invasive cardiac procedures were not available in many of the centers. Many cases of ischemic heart disease may have been missed. In addition, standard cardiac procedures performed in these subjects were not captured by our study.

In conclusion, there are unique gender differences in the presentation of HF in sub-Saharan Africa. Male subjects are generally older than women which are the reverse in high-income countries where women are about 6 years older than men. Before the age of 50 years, HF was diagnosed more often in women, but thereafter in men. Except for valvular heart disease and peripartum cardio- 
Fig. 3 Kaplan-Meier survival plot for outcome death to day 180 comparing the two genders

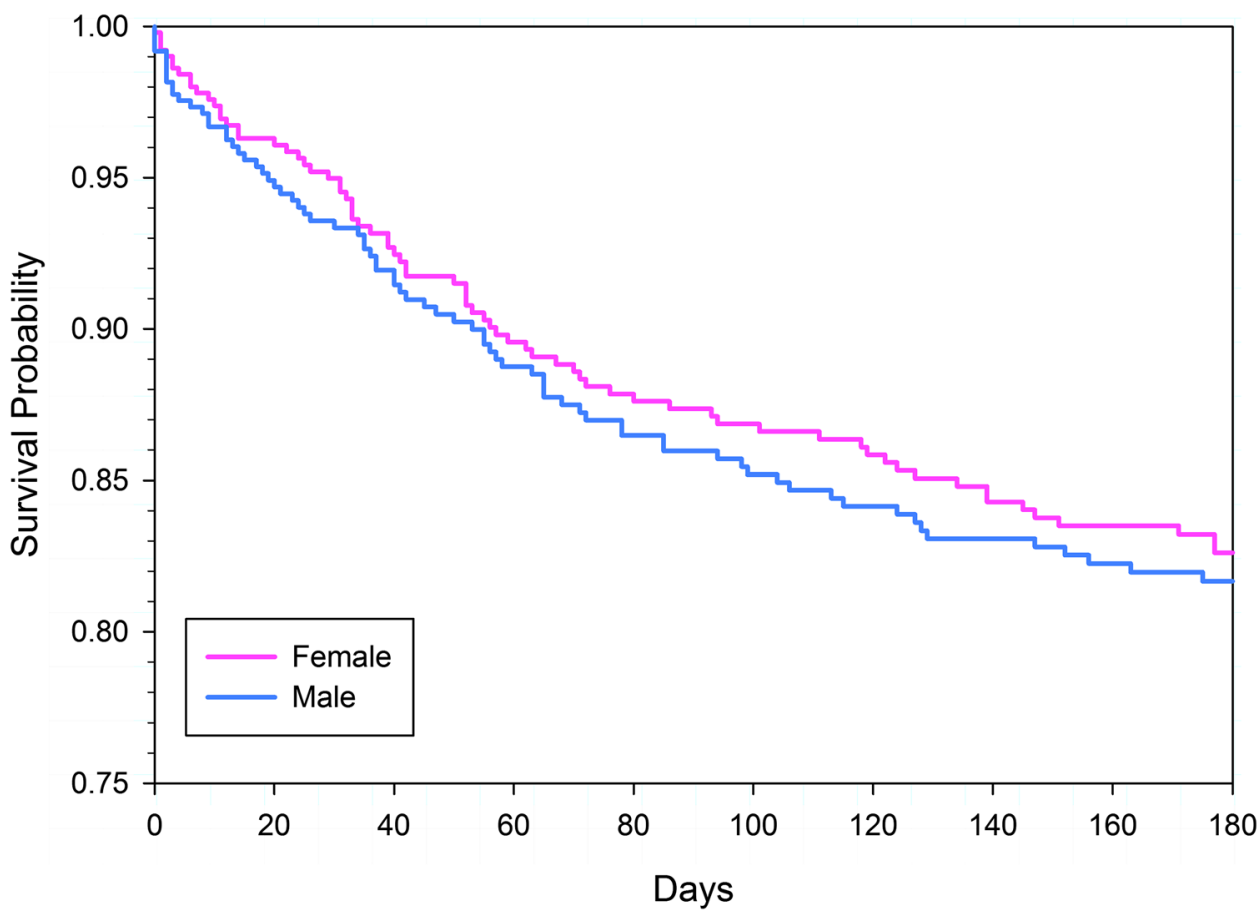

myopathy, other etiological risk factors were commoner in men. Men also had higher frequency of systolic HF, renal dysfunction, but lower frequency of anemia than women. Drug prescriptions at admission or discharge were relatively similar. Outcomes were slightly worse in men, but these were not statistically significant.

These findings call for individualized care for patients in the region especially the male gender that is likely to have multiple cardiovascular risk factors.

Acknowledgments We want to thank all the health workers who contributed in no small way to the success of this work.

Conflict of interest None.

\section{References}

1. Stewart S, MacIntyre K, Hole DJ et al (2001) More 'malignant' than cancer? Five-year survival following a first admission for heart failure. Eur J Heart Fail 3(3):315-322

2. Bui AL, Horwich TB, Fonarow GC (2011) Epidemiology and risk profile of heart failure. Nature reviews. Cardiology 8(1):30-41

3. Roger VL, Go AS, Lloyd-Jones DM et al (2011) Heart disease and stroke statistics-2011 update: a report from the American Heart Association. Circulation 123(4):e18-e209

4. Gheorghiade M, Zannad F, Sopko G et al (2005) Acute heart failure syndromes: current state and framework for future research. Circulation 112(25):3958-3968

5. Fonarow GC, Abraham WT, Albert NM et al (2009) Age- and gender-related differences in quality of care and outcomes of patients hospitalized with heart failure (from OPTIMIZE-HF). Am J Cardiol 104(1):107-115
6. Galvao M, Kalman J, DeMarco T et al (2006) Gender differences in in-hospital management and outcomes in patients with decompensated heart failure: analysis from the Acute Decompensated Heart Failure National Registry (ADHERE). J Card Fail 12(2):100-107

7. Brandsaeter B, Atar D, Agewall S et al (2011) Gender differences among Norwegian patients with heart failure. Int $\mathrm{J}$ Cardiol 146(3):354-358

8. Tsuchihashi-Makaya M, Hamaguchi S, Kinugawa S et al (2011) Sex differences with respect to clinical characteristics, treatment, and long-term outcomes in patients with heart failure. Int $\mathbf{J}$ Cardiol 150(3):338-339

9. Smilde TD, Damman K, van der Harst P et al (2009) Differential associations between renal function and "modifiable" risk factors in patients with chronic heart failure. Clin Res Cardiol Off J Ger Card Soc 98(2):121-129

10. Damasceno A, Mayosi BM, Sani M et al (2012) The causes, treatment, and outcome of acute heart failure in 1006 Africans from 9 countries. Arch Intern Med 172(18):1386-1394

11. Rits IA (1964) Declaration of Helsinki. Recommendations Guidings Doctors in Clinical Research. World Med J 11:281

12. Dickstein K, Cohen-Solal A, Filippatos G et al (2008) ESC guidelines for the diagnosis and treatment of acute and chronic heart failure 2008: the Task Force for the diagnosis and treatment of acute and chronic heart failure 2008 of the European Society of Cardiology. Developed in collaboration with the Heart Failure Association of the ESC (HFA) and endorsed by the European Society of Intensive Care Medicine (ESICM). Eur J Heart Fail 10(10):933-989

13. McMurray JJ, Adamopoulos S, Anker SD et al (2012) ESC Guidelines for the diagnosis and treatment of acute and chronic heart failure 2012: The Task Force for the diagnosis and treatment of acute and chronic heart failure 2012 of the European Society of Cardiology. Developed in collaboration with the Heart Failure Association (HFA) of the ESC. Eur Heart J 33(14):1787-1847

14. Henry WL, DeMaria A, Gramiak R et al (1980) Report of the American society of echocardiography committee on 
nomenclature and standards in two-dimensional echocardiography. Circulation 62(2):212-217

15. Sahn DJ, DeMaria A, Kisslo J et al (1978) Recommendations regarding quantitation in M-mode echocardiography: results of a survey of echocardiographic measurements. Circulation 58(6):1072-1083

16. Sliwa K, Hilfiker-Kleiner D, Petrie MC et al (2010) Current state of knowledge on aetiology, diagnosis, management, and therapy of peripartum cardiomyopathy: a position statement from the Heart Failure Association of the European Society of Cardiology Working Group on peripartum cardiomyopathy. Eur J Heart Fail 12(8):767-778

17. Pearson GD, Veille JC, Rahimtoola S et al (2000) Peripartum cardiomyopathy: National Heart, Lung, and Blood Institute and Office of Rare Diseases (National Institutes of Health) workshop recommendations and review. JAMA 283(9):1183-1188

18. Nieminen MS, Harjola VP, Hochadel M et al (2008) Gender related differences in patients presenting with acute heart failure. Results from EuroHeart Failure Survey II. Eur J Heart Fail 10(2):140-148

19. Spinar J, Spinarova L (2009) Gender differences in acute heart failure. Future cardiology 5(2):109-111

20. Mayosi BM (2007) Contemporary trends in the epidemiology and management of cardiomyopathy and pericarditis in sub-Saharan Africa. Heart 93(10):1176-1183

21. Damasceno A, Cotter G, Dzudie A et al (2007) Heart failure in sub-Saharan Africa: time for action. J Am Coll Cardiol 50(17):1688-1693

22. Klapholz M, Maurer M, Lowe AM et al (2004) Hospitalization for heart failure in the presence of a normal left ventricular ejection fraction: results of the New York Heart Failure Registry. J Am Coll Cardiol 43(8):1432-1438

23. Okello E, Wanzhu Z, Musoke C et al (2013) Cardiovascular complications in newly diagnosed rheumatic heart disease patients at Mulago Hospital Uganda. Cardiovasc J Afr 24(3):80-85

24. Zhang W, Mondo C, Okello E et al (2013) Presenting features of newly diagnosed rheumatic heart disease patients in Mulago Hospital: a pilot study. Cardiovasc J Afr 24(2):28-33

25. Stewart S, Wilkinson D, Hansen C et al (2008) Predominance of heart failure in the Heart of Soweto Study cohort: emerging challenges for urban African communities. Circulation 118(23):2360-2367

26. Okin PM, Devereux RB, Nieminen MS et al (2006) Electrocardiographic strain pattern and prediction of new-onset congestive heart failure in hypertensive patients: the losartan intervention for endpoint reduction in hypertension (LIFE) study. Circulation 113(1):67-73

27. Okin PM, Devereux RB, Nieminen MS et al (2004) Electrocardiographic strain pattern and prediction of cardiovascular morbidity and mortality in hypertensive patients. Hypertension 44(1):48-54

28. Badano L, Rubartelli P, Giunta L et al (1994) Relation between ECG strain pattern and left ventricular morphology, left ventricular function, and DPTI/SPTI ratio in patients with aortic regurgitation. J Electrocardiol 27(3):189-197

29. Adams KF Jr, Sueta CA, Gheorghiade M et al (1999) Gender differences in survival in advanced heart failure. Insights from the FIRST study. Circulation 99(14):1816-1821

30. Gustafsson F, Torp-Pedersen C, Burchardt H et al (2004) Female sex is associated with a better long-term survival in patients hospitalized with congestive heart failure. Eur Heart $\mathbf{J}$ 25(2):129-135

31. Rathore SS, Foody JM, Wang Y et al (2005) Sex, quality of care, and outcomes of elderly patients hospitalized with heart failure: findings from the National Heart Failure Project. Am Heart J 149(1):121-128. doi:10.1016/j.ahj.2004 